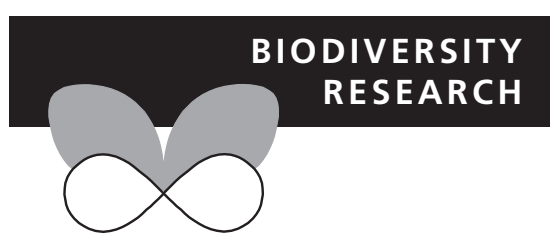

\title{
Is phylogenetic relatedness to native species important for the establishment of reptiles introduced to California and Florida?
}

Nicola J. van Wilgen` and David M. Richardson

Centre for Invasion Biology, Department of Botany and Zoology, Stellenbosch University, P/Bag X1, Matieland, 7602, South Africa

${ }^{*}$ Correspondence: Nicola J. van Wilgen, Centre for Invasion Biology, Department of Botany and Zoology, Stellenbosch University, P/Bag X1, Matieland, 7602, South Africa. E-mail: nvanwilgen@gmail.com

\begin{abstract}
Aim Charles Darwin posited that introduced species with close relatives were less likely to succeed because of fiercer competition resulting from their similarity to residents. There is much debate about the generality of this rule, and recent studies on plant and fish introductions have been inconclusive. Information on phylogenetic relatedness is potentially valuable for explaining invasion outcomes and could form part of screening protocols for minimizing future invasions. We provide the first test of this hypothesis for terrestrial vertebrates using two new molecular phylogenies for native and introduced reptiles for two regions with the best data on introduction histories.
\end{abstract}

Location California and Florida, USA.

Methods We performed an ordination of ecological traits to confirm that ecologically similar species are indeed closely related phylogenetically. We then inferred molecular phylogenies for introduced and native reptiles using sequence data for two nuclear and three mitochondrial genes. Using these phylogenies, we computed two distance metrics: the mean phylogenetic distance (MPD) between each introduced species and all native species in each region (which indicates the potential interactions between introduced species and all native species in the community) and the distance of each introduced species to its nearest native relative - NN (indicating the degree of similarity and associated likelihood of competition between each introduced species and its closest evolutionary analogue). These metrics were compared for introduced species that established and those that failed.

Results We demonstrate that phylogenetically related species do share similar ecological functions. Furthermore, successfully introduced species are more distantly related to natives (for NN and MPD) than failed species, although variation is high.

Main conclusions The evolutionary history of a region has value for explaining and predicting the outcome of human-driven introductions of reptiles. Phylogenetic metrics are thus useful inputs to multi-factor risk assessments, which are increasingly required for screening introduced species.

\section{Keywords}

Alien species, biological invasions, competition, Darwin's naturalization hypothesis, novel species, phylogenetic distance, phylogeny.

\section{INTRODUCTION}

Escalating global change is increasing the urgency of quests to unravel the relative roles played by a multitude of factors in structuring biological communities. Invasion biology has tried to explain the factors that determine why some, but not all, introduced species establish invasive populations. Some broad patterns have emerged: species tend to invade in regions with 
similar climates (Bomford et al., 2009; van Wilgen et al., 2009), when they are released from their natural predators (Elton, 1958; Strong et al., 1984; Mack et al., 2000), and when a large number of individuals are introduced to the new region, multiple times (Lockwood et al., 2005; Duggan et al., 2006; Reaser et al., 2008; Simberloff, 2009). However, these variables may be difficult to quantify, and very few authors have provided a practical means for predicting which species are likely to become established. Consequently, measures that are easy to quantify and provide robust predictions are required (Ricciardi \& Mottiar, 2006). One issue that has long intrigued ecologists in this regard is the importance of resident biota in mediating the openness of ecosystems to new members. The presence of closely related species may be beneficial (i.e. facilitating) if it provides the opportunity for mutualistic relationships (such as pollination; Richardson et al., 2000). It may also indicate the presence of relevant resources (a suitable 'niche') (Webb, 2000; Duncan \& Williams, 2002). However, closely related species may be host to diseases or sustain predator populations that would also likely infect or prey on the new introduced species (Mack, 1996). Furthermore, similarity between species increases the likelihood of competition for shared resources (Darwin, 1859).

Charles Darwin was one of the first to consider the implications of native biota for mediating the establishment success of introduced species when he showed that trees introduced to North America were more likely to establish and proliferate if they belonged to genera other than those that occurred naturally in the United States (Darwin, 1859). He concluded that introduced species with close native relatives were less likely to succeed in new environments because of fiercer competition arising from their similar life histories and ecologies. This pattern has been supported as well as refuted in recent literature, and determining the spatial, temporal and taxonomic scales at which the pattern is observed is currently of great interest (e.g. Duncan \& Williams, 2002; Strauss et al., 2006; Diez et al., 2008). Tests of 'Darwin's naturalization hypothesis' sensu Daehler (2001) have however been inconsistent (Thuiller et al., 2010). Procheş et al. (2008) summarize four approaches implemented to test for phylogenetic patterns in invasions that have been loosely grouped under the umbrella of tests of 'Darwin's naturalization hypothesis'. In each of these approaches, a different underlying hypothesis is tested. The first focuses on the region to which species are introduced and compares the number of successfully introduced species with and without native counterparts belonging to the same genus [e.g. Darwin (1859) who found a negative association between presence of congeners and established species]. The second focuses on the pool of non-indigenous species available to be introduced and tests whether the naturalized species are a random sample from this pool or whether successful species are biased by indigenous congeners in the new region [e.g. Rejmánek (1996), who found support for Darwin's findings]. The third type of study focuses on the success of species relative to the presence of congeners and tests whether successfully introduced species are more likely to have congeners in the new range than species that are introduced but fail to establish. An example is provided by Ricciardi \& Mottiar (2006), who in exploring the role of native species in mediating the success of fish introductions, found no evidence in support of or against the naturalization hypothesis (i.e., ratios of shared and unshared genera were similar for failed and successful introductions). Finally, a fourth approach expands on the previous one by incorporating phylogenetic branch length as a measure of relatedness, testing whether successfully or unsuccessfully introduced species have closer relatives in the new range. Strauss et al. (2006) were the first, and until now the only study as far as we know, to incorporate phylogenetic information in a test of this kind.

There has been a significant taxonomic bias in previous tests of Darwin's naturalization hypothesis, with all studies besides Ricciardi \& Mottiar (2006) focusing on plants and none on terrestrial vertebrates. Here, we provide the first test of Darwin's naturalization hypothesis for terrestrial vertebrates. We aim to determine whether the presence of close relatives influences reptile establishment for species introduced to California and Florida and whether this might be useful for explaining and predicting species invasions. Advances in molecular techniques and increased availability of DNA sequence data over the last decade have made it feasible to construct a molecular phylogeny spanning all reptile groups in California and Florida, including species introduced to these regions through human activity in the past century. We chose California and Florida because both regions have received many introductions, and because the fate of these introductions has been well documented (Kraus, 2009).

Testing Darwin's naturalization hypothesis is especially important for reptiles, as their importance as pets and as invasive species is increasing rapidly world-wide (Kraus, 2009; van Wilgen et al. 2010). Sound ecological information on which to base objective decisions for risk assessment is urgently needed. This should preferably be obtainable from existing and widely available sources, because it is impractical to conduct field research each time a risk assessment is undertaken. Although several other explanatory variables have been identified as being useful in screening species for invasiveness, a significant portion of variation seen in establishment success remains unexplained. It is therefore important to explore additional explanatory variables and to determine the value of readily available data for making predictions. Here, we show a trend in establishment indicating that species with more distant relatives, i.e. those that are phylogenetically novel, are more likely to establish than those with closer relatives, which are less novel. Our sample of introduced species is limited and may be influenced by phylogenetic non-independence, highlighting the possibility that observed patterns perhaps have less to do with relatedness of introduced species to native ones, but rather relatedness of successful species to one another, with a select few taxonomic groups being more likely to invade than others. Nevertheless, data from our work add a new dimension to current interpretations of invasion patterns and provide an opportunity to incorporate ecological interactions into the 
prediction of future introduction outcomes (the roles of which have largely been overlooked as these are notoriously difficult to quantify). The increase in available literature pertaining to relatedness among and between different groups of species from all taxonomic groups provides increased opportunity for creating supertree and gene tree phylogenies, in turn allowing the incorporation of this important explanatory variable into the analysis of species establishment potential.

\section{METHODS}

Exploring Darwin's naturalization hypothesis using phylogenetic relatedness assumes that this metric is a convenient proxy for ecological similarity. However, closely related species do not always use their habitat and environment in the same way, which may result in phylogenetic relatedness not mapping predictably onto ecological similarity. To assess our use of phylogenetic similarity in this context, we gathered data on 37 ecological traits for each native and introduced species and used these data to determine whether groups of species that have similar ecologies are indeed closely related phylogenetically. Ordination analyses were performed in R v. 2.10.1 (R Development Core Team, 2010) using the functions vegdist and metaMDS (package vegan, 1.17-0; Oksanen et al., 2010), and outputs were produced in the form of both plots and dendrograms. Because this was not the primary focus of this paper, our methods are detailed in the supplementary material (Appendix S1, section S1.1).

For the phylogenetic analyses, we could not find a reptile phylogeny spanning the breadth of reptile taxa native and introduced to California and Florida. Therefore, we started by constructing a family-level supertree based on the consensus of existing phylogenies to use as a reference. This tree provided us with a basic understanding of the relationships among reptile groups. However, because such a tree has no branch length information, we sought sequence data to produce a more detailed phylogeny. Sequences were downloaded from GENBANK where available for both native and introduced alien species in California and Florida for two nuclear (cmos, 46\% missing data and RAG1, 54\% missing data) and three mitochondrial genes (ND2, 45\% missing data, ND4, 40\% missing data, and cytb, 14\% missing data) (see Appendix S2 for accession numbers). Sequences were aligned using BioEdit v. 7.0.9 (Hall, 1999) and Se-Al v.2 (Rambaut, 1996). MrModeltest v.2.3 (Nylander, 2004) was used to assess the appropriate models to use for nucleotide substitution for each gene. Separate phylogenies were inferred for each gene as well as for the entire dataset for California and Florida using Bayesian analyses in MrBayes v. 3.1.2 (Huelsenbeck \& Ronquist, 2001). Analyses on the full dataset were run for 1,000,000 (California) and 1,300,000 (Florida) generations, sampled every 100 generations, using five chains. We discarded all samples obtained prior to stationarity as burn-in (3000 samples for the California tree and 6000 for the Florida tree), that is the last 7000 trees (samples) were used to construct 50\% majority rule consensus trees for each region. Only the species for which at least two of the five genes of interest were available were included in these trees (this constituted $85 \%$ of native and introduced species in California and $70 \%$ in Florida). The remaining species were added to the phylogenies afterwards, using Mesquite v. 2.71 (Maddison \& Maddison, 2009). These species were positioned on the basis of available literature and individual gene trees where data were available for one gene (see Table S1). Placement of the Acrodonta (Cope 1860, Agamidae and Chamaeleonidae) proved problematic. This group has evolved relatively fast increasing the chance of longbranch attraction (Vidal \& Hedges, 2005), the phenomenon where groups that evolve faster accumulate more mutations or DNA substitutions than those that evolve slowly, which over time may result in shared DNA sequences by chance rather than common ancestry. As a result, the analysis placed the group basal to the snakes instead of the rest of the iguanid group. We therefore included this group basal to iguanids subsequent to the analyses, although our results were not much affected by the choice of tree.

Introduced species were grouped as failed or established based on available literature and online databases and lists (including: King et al., 1996-2010; Florida Fish and Wildlife Conservation Commission, 1999-2010, Nafis, 2000-2010; Meshaka et al., 2004; Kraus, 2009); these data were checked by herpetologists in the region (see Acknowledgements). We acknowledge that there may be some introduced species that we have missed or have excluded because of contradictory reports on their establishment. However, we feel that we have a very representative sample of introduced species in both regions. Phylocom (Webb et al., 2008) was used to calculate two distance metrics on the trees, using the function ICOMDIST (see Strauss et al., 2006). First, we calculated the mean phylogenetic distance (MPD) between each introduced species and all native species in each region (California or Florida). This indicated the potential interactions among introduced species and all native species in the community. Second, we calculated the distance of each introduced species to its nearest native neighbour/relative $(\mathrm{NN})$. This allowed for a more direct (and robust) test of Darwin's hypothesis by indicating the degree of similarity and associated likelihood of competition between each introduced species and its closest evolutionary analogue. A nonparametric Kolmogorov-Smirnov two-sample test was used to test for differences in MPD and $\mathrm{NN}$ between successfully introduced species (those where extant breeding populations still occurred) and species that had failed to establish. The tests were repeated using 1000 bootstraps of randomly resampled data to account for potential phylogenetic non-independence of successful or failed species. All analyses were run using both trees with and without the addition of the data-deficient taxa (those for which $<2$ genes were available). We also calculated the overall phylogenetic diversity (PD; Faith, 1992) of native reptiles in both California and Florida because lower PD may predispose communities to invasion.

Last, because established introduced species could interact with subsequently introduced ones in a similar way to native 
species, we re-evaluated MPD and NN for each species including the species that had been established for at least 5 years prior to the subsequent introduction of new species in the same category as natives (see Appendix S1, section S1.2 in Supporting Information). However, this was done for completeness, because most species established in California and Florida have not had sufficient residence time to become widespread enough to have significant impact in this regard, making it unlikely that this factor will complicate our results and interpretations.

\section{RESULTS}

To our knowledge, our trees represent the first exclusively molecular phylogenies that span all reptiles. The trees obtained for California and Florida reptiles were congruent with the available literature (and our supertree - see methods) (Fig. 1; Figs S1 \& S2). Several polytomies have been reported in the literature and we were unable to find strong support to resolve these [e.g., the relationship between anguimorphs, snakes and iguanids (Townsend et al., 2004; Vidal \& Hedges, 2005) as well as the inter-relationships within the Iguania (Schulte et al., 2003)]. The placement of the Acrodonta (Agamidae and Chamaeleonidae) was somewhat problematic because of longbranch attraction, but was dealt with as detailed in the methods.

Initial analysis of the dataset showed that the distribution of the MPD for failed species was left-skewed, i.e. most failed species had low MPD, whereas the distribution for successful species was more normally distributed (Fig. 2a). A similar, though more pronounced, pattern was observed for the nearest neighbour (NN) distances (Fig. 2b). In Florida, established alien species were significantly more distantly related to native species from the entire reptile community than species that failed to establish, although there was high variation among species (average MPD for established species: 1.27 units \pm 0.20 $\mathrm{SD}, n=39 ; \mathrm{MPD}$ failed species $=1.15$ units $\pm 0.14 \mathrm{SD}$, $n=43 ; P=0.006)$. There was no significant difference between the mean nearest neighbour distance of established and failed species because of a high variation in successful species, although failed species tended to be more closely related to native species (Fig. 2b; average NN established species: 1.12 units $\pm 0.89 \mathrm{SD}, n=39$; average $\mathrm{NN}$ failed species $=0.84$ units $\pm 0.77 \mathrm{SD}, n=43 ; \quad P=0.1)$. Trends were similar, although non-significant in California; this was probably as a result of a very small sample of established species $(n=49,8$ established, 41 failed). When data from both regions were combined, reptiles that were more distantly related to the entire reptile community were significantly more likely to establish (average MPD established species: 1.29 units \pm 0.20 SD, $n=47$; average MPD failed species: $1.20 \pm 0.18 \mathrm{SD}, n=87$; $P=0.02$; Fig. 2a), and again this was also true of the relationship between introduced species and their closest native relatives (average NN established species $=0.99$ units \pm 0.87 $\mathrm{SD}, n=47$; average NN failed species $=0.64$ units $\pm 0.65 \mathrm{SD}$, $n=87$; $P=0.01$; Fig. 2b). Bootstrapping (randomization) of the samples had no significant effect on the KolmogorovSmirnov statistic. The test statistic obtained from both the test of the effect of MPD and NN on establishment outcome fell well within the $95 \%$ bootstrap confidence intervals. Results from the analyses using successfully introduced species in the same capacity as natives were inconclusive and can be found in Appendix S1 (section S1.2).

The ordination analyses that sought to determine whether phylogenetically related species shared common ecological functions showed a high level of clustering at genus, family and order levels. This provides good evidence that the ecological traits considered in this analysis are phylogenetically conserved at these levels, and that patterns emerging from our phylogenetic analysis are ecologically meaningful. However, although ordination of ecological traits did identify higher-order taxonomic groups (e.g. all turtles clustered together), separation of these groups in space did not reflect the relationships between these groups as clearly (Fig. 3 and Fig. S3 - California and Fig. S4 - Florida). For example, in the ordination analysis, crocodiles clustered closer to snakes that occur in or spend part of their active period in water, despite being more closely related to the turtle group that clustered further away. There are few native Gekkonid and Iguanid species in Florida, but many introduced species from these groups, while the opposite is true in California (Fig. 3). Two species stood out as being relatively far removed from other species belonging to their respective taxonomic groups and indeed far from any other species. These were a native Californian sea-snake (Pelamis platurus, Serpentes) and a lizard introduced to Florida (Cordylus cordylus, Iguania). Both these species are ecologically and phylogenetically quite different to all the other native and introduced species.

\section{DISCUSSION}

Our results provided weak support for Darwin's naturalization hypothesis (i.e. the preferential establishment of ecologically novel species) - the first evidence of this for terrestrial vertebrates. We will first discuss the most plausible reasons for finding such a pattern before expanding on the potential shortfalls of these explanations in the light of the high variation observed (Fig. 2) and the limited phylogenetic sample of introduced species. The preferential establishment of species with no close relatives is typically interpreted to be the result of one of three processes. The first is competitive exclusion. This has been documented for several reptile invasions. For example, introduced gecko species from the genus Hemidactylus have outcompeted previously established congeners in Florida (Meshaka et al., 2005, 2006) (with more examples in other areas). These initial invaders would perhaps not have been successful had the order of introduction been reversed. Species in our study that failed to establish may have been prevented from doing so by superior closely related native competitors (low NN distance), while species with more distantly related ancestors (higher NN) would be less affected by direct competitors, possibly allowing them to establish. 


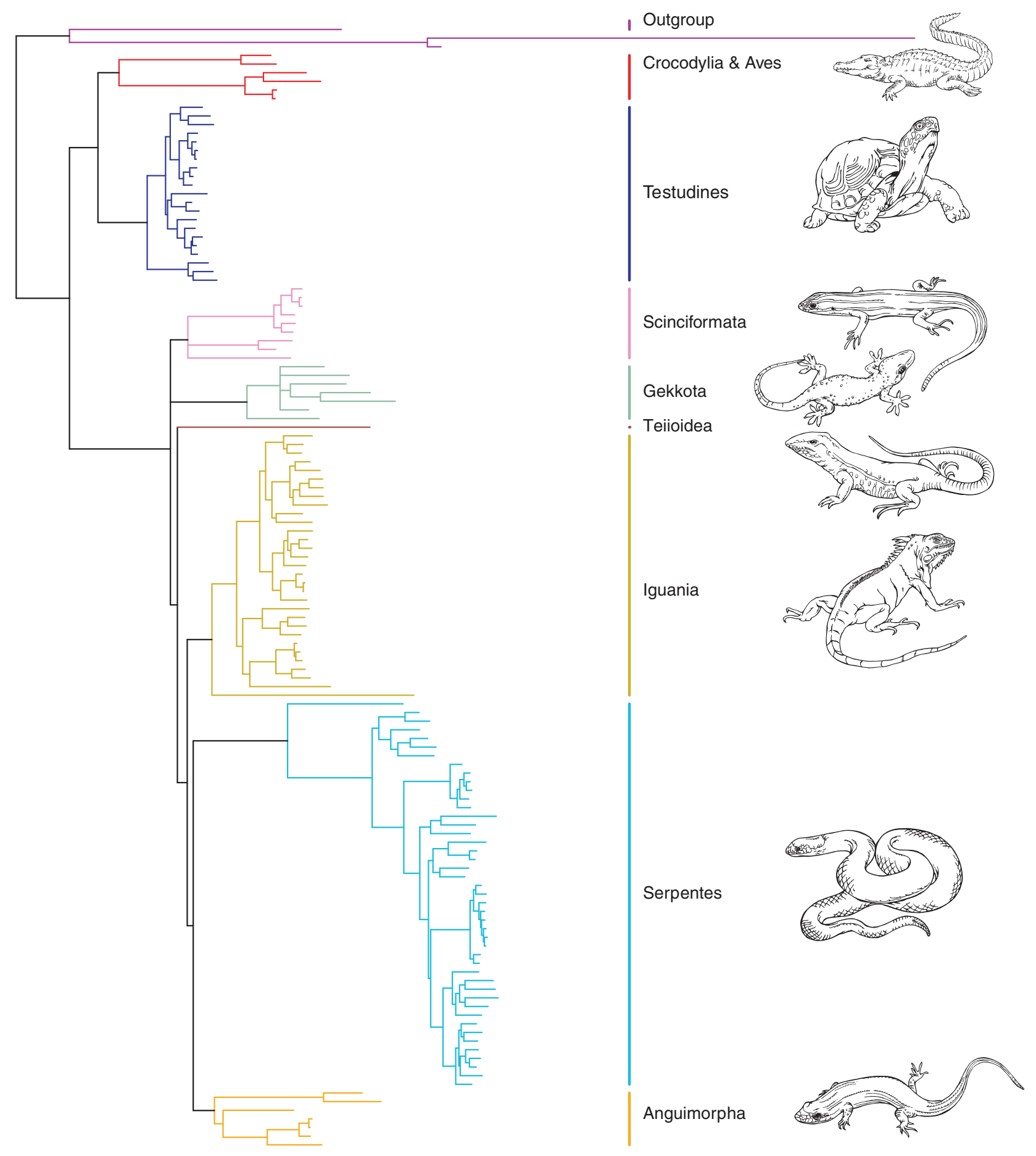

Figure 1 Phylogenetic relationships of reptiles native and introduced to California inferred from two nuclear (c-mos and RAG 1) and three mitochondrial genes (cytb, ND2 and ND4). This tree was obtained from MrBayes Bayesian analyses and does not include added taxa. Branches are proportional to the number of DNA changes. Groups are colour-coded by order, suborder or infraorders as in Vidal \& Hedges (2005). More detailed trees for California and Florida including added taxa are available as supporting information (Figs S1 \& S2).

Secondly, the presence of closely related species may also increase the chance of predation and the spread of host-specific parasites and diseases. Furthermore, species may be more susceptible to disease where competition is higher (Irschick et al., 2006, although this study looked at intra-specific competition). Disease transmission from native to alien species is however rarely documented, with research effort focusing on the transmission of new diseases from alien to native species (e.g. Oliver et al., 1993; Burridge et al., 2000). 
Figure 2 (a) Distribution of the mean phylogenetic distance (MPD) between alien reptiles introduced to California and Florida and species native to these states. (b) Distribution of the phylogenetic distance between introduced reptiles and the nearest native neighbour/relative $(\mathrm{NN})$ in California and Florida. White bars indicate species that successfully established populations, and black bars indicate species that failed.

Figure 3 Two-dimensional ordination of 37 ecological variables, indicating the relative position of species in ecological space in (a) California and (b) Florida. Each dot represents a species. Species are colour-coded by higher order as in Fig. 1. Further, established introduced species are circled in black, while failed introduced species are circled in grey. Native species are not circled.
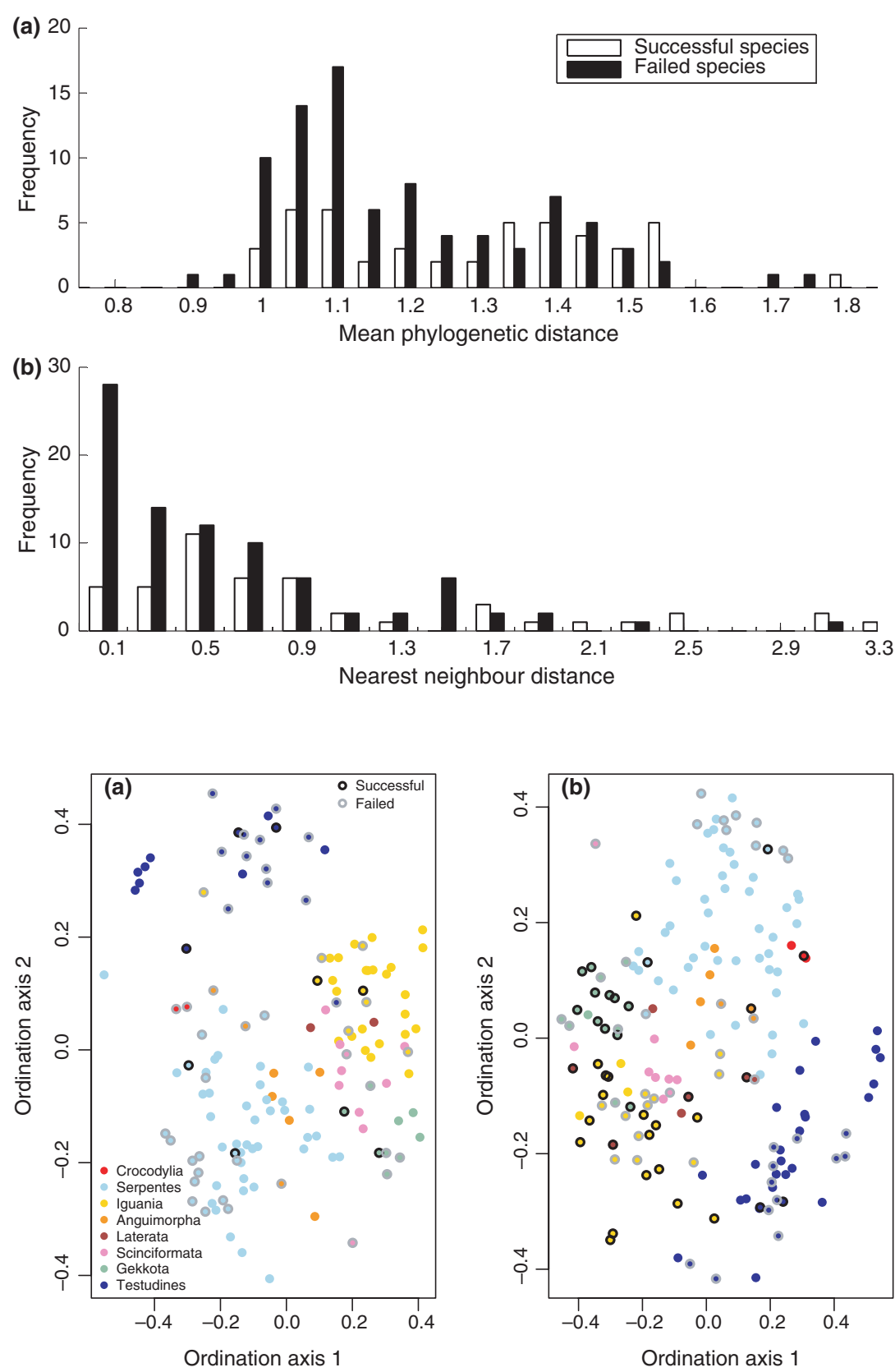

The third process is more complex: in addition to release from competition, introduced species may, if sufficiently different from natives (high NN and high MPD), also be able to exploit unoccupied niches (Reed \& Rodda, 2009). A classic example is the brown tree snake (Boiga irregularis), which devastated the local fauna on the island of Guam, although the phenomenon of 'island tameness' - the lack of adaptation to predators - was crucial in this case (Fritts \& Rodda, 1998). The case of birds introduced to Florida presents a less extreme and more instructive example. Allen et al. (1999) and Allen (2006) showed that native bird species in southern Florida can be grouped discontinuously in body size aggregations and that successfully introduced birds aggregated at the edge of these body size aggregations and were also significantly more dissimilar in size to native species than were unsuccessful species. Species within these size aggregations are expected to compete for similar resources, although perhaps at different scales. Dissimilar species may therefore escape competition through novel utilization of available resources. Python molurus (the Burmese python) provides a good reptile example. Florida has no native boas or pythons and indeed no constricting snakes that grow to the size of the introduced Burmese python. The ecological ordination illustrates that boid species (boas and pythons) cluster together but separately from native snakes (Fig. 3, top cluster of introduced species). Of these species, the Burmese python has had the highest propagule pressure (Kraus, 2009) and was in the best position to exploit the 
unoccupied Florida niche, while encountering almost no predators.

As our study considered only presence/absence at the scale of the whole states (California and Florida), it is very unlikely that a given introduced species actually experienced contact with all potential competitors. The fact that we detected a pattern at all indicates that forces operating across multiple spatial scales must be implicated. Large regions of Florida and some regions of California are highly disturbed, and low abundances of native species have been documented throughout Florida (Meshaka et al., 2004). Therefore, in many instances, we are observing the ability of species to survive and compete in human-modified areas. Species that evolved or have adapted locally (native and introduced) may no longer be favoured in competitive interactions. Thus, the trend in success documented here (i.e. a tendency for successful species to be novel) may result when more distantly related species from further afield, which are perhaps not pre-adapted to survive in natural environments in California and Florida, can survive in disturbed areas where certain key limiting factors are reduced/ eliminated. Furthermore, habitat disturbance may reduce the variety of niches available to species, increasing resource niche overlap (Luiselli, 2006). Where habitat use may be partitioned (Harmon et al., 2007) between similar sympatric species in pristine environments, the disturbed nature of many of the habitats available to invaders in Florida and some parts of California may increase competitive interactions, reinforcing the exclusion of similar species and those that are preferentially adapted to more pristine environments. Lastly, the overall PD of a region may play some role in mediating whether introduced species are likely to meet a superior competitor. In regions with higher $\mathrm{PD}$, the likelihood of meeting a competitor is greater. Although we have no data from other regions, the low PD of Florida (0.439) compared to that of California (0.677) could contribute to the high number of invaders in the region (although the higher introduction pressure in Florida complicates the evaluation of the role of this factor).

Having discussed a series of possible explanations for the preferential establishment of less closely related species, we need to consider the substantial variation in NN and MPD for both failed and successful species and that many of the successful species are closely related (e.g. anoles and geckos). Elucidation of the latter caveat is crucial for interpreting all past and future tests of Darwin's hypothesis. Several studies across multiple taxa have shown that certain lineages are simply more invasive than others and succeed at much higher rates when introduced to new areas (Pyšek, 1998; Richardson \& Rejmánek, 2004; Cadotte et al., 2006: plants; Bomford et al., 2009: reptiles and amphibians; Shirley \& Kark, 2009: birds). The trends seen in the phylogenetic signal are most likely masking the dominant role of taxon-specific traits in a few notoriously successful invader groups. The ordination analysis provides a neat representation of this. For example, Gekkonids and Iguanids, represented by a comparatively depauperate native fauna (Fig. 3), have been introduced to Florida in comparatively high numbers. The high number of introductions from these ecologically and phylogenetically unique groups may account for the observed pattern of novel species being more successful.

Although rigorous tests of Darwin's hypothesis are rare, with many performing tests based on presence/absence of species using membership of a genus as a surrogate for relatedness, as Darwin did, the increase in the availability of robust molecular phylogenies will undoubtedly change this. Nearly all tests of this hypothesis and indeed $44 \%$ of all invasion biology papers recorded by the Web of Science, up to September 2006, dealt with plants, only 15\% dealt with vertebrates and $2 \%$ with 'reptiles and amphibians' (Pyšek et al., 2008) [of which a very large proportion deal with only two amphibian species - Rhinella marina and Xenopus laevis which makes the under-representation of reptile studies even more striking]. There is clearly a need for more work to be carried out before robust conclusions can be reached and general rules laid down regarding vertebrate (and especially reptile) invasions. The increasing use of molecular phylogenies will play an important role in doing so. It is very important that future studies consider the effect of phylogenetic non-independence of samples (Felsenstein, 1985), and that phylogenetic measures may be masking the true causes of observed invasion patterns, if species are closely related.

Although we cannot identify a specific mechanism for the pattern we observed and our interpretation of the patterns may be clouded by non-independence, our results nonetheless have important implications. These results set the platform for further studies to explore the role of biotic interactions in structuring vertebrate assemblages, whose dynamics have mostly been studied with reference to predator-prey relationships and competitive interactions (Vellend, 2010; who proposed some interesting alternatives). Simple models invoking degrees of phylogenetic similarity/dispersion may be able to explain just as much variation as traditional ones. Again, most of the current literature on phylogenetic perspectives of community composition deals with plants and invertebrates, although we hope that our work will stimulate further work in this direction for vertebrate communities. Reptiles (and other vertebrates) are increasingly traded globally as pets. There are mounting concerns about the role of this trade in introducing potentially invasive species, pests and pathogens (van Wilgen et al. 2010). Very few data are available on how reptile species behave in new environments and factors that may be useful in risk assessments are often difficult to quantify or are poorly understood (Bomford et al., 2009; van Wilgen et al. 2010). Our results suggest that an easy-to-measure phylogenetic perspective could be incorporated into multi-factor risk assessment models.

\section{ACKNOWLEDGEMENTS}

We thank Anne Ropiquet for advice on sequence alignments, Anne Ropiquet, Bettine van Vuuren and Marc Cadotte for advice on phylogenetic analyses, Walter Meshaka, Sam 
Bacchini and Scott Hardin for commenting on species invasion success and relevant websites in Florida and California, Peter le Roux for comments on ordination analysis, Sindiso Nyoni for sketching the reptiles, and Ralph MacNally, Tony Ives and several anonymous reviewers for helpful comments and suggestions. Financial support for this work came from the Australian Centre of Excellence for Risk Analysis (ACERA) (N.J.v.W.), the DST-NRF Centre of Excellence for Invasion Biology (South Africa), the Wilhelm Frank Bursary Fund (N.J.v.W.), Cape Action for People and the Environment (C.A.P.E.) and the Hans Sigrist Foundation (D.M.R.).

\section{REFERENCES}

Allen, C.R. (2006) Predictors of introduction success in the South Florida avifauna. Biological Invasions, 8, 491500.

Allen, C.R., Forys, E.A. \& Holling, C.S. (1999) Body mass patterns predict invasions and extinctions in transforming landscapes. Ecosystems, 2, 114-121.

Bomford, M., Kraus, F., Barry, S.C. \& Lawrence, E. (2009) Predicting establishment success for alien reptiles and amphibians: a role for climate matching. Biological Invasions, 11, 713-724.

Burridge, M.J., Simmons, L.A. \& Allan, S.A. (2000) Introduction of potential heartwater vectors and other exotic ticks into Florida on imported reptiles. Journal of Parasitology, 86, 700-704.

Cadotte, M.W., Murray, B.R. \& Lovett-Doust, J. (2006) Ecological patterns and biological invasions: using regional species inventories in macroecology. Biological Invasions, 8, 809-821.

Daehler, C.C. (2001) Darwin's naturalization hypothesis revisited. American Naturalist, 158, 324-330.

Darwin, C. (1859) On the origin of species by means of natural selection. J. Murray, London.

Diez, J.M., Sullivan, J.J., Hulme, P.E., Edwards, G. \& Duncan, R.P. (2008) Darwin's naturalization conundrum: dissecting taxonomic patterns of species invasions. Ecology Letters, 11, 674-681.

Duggan, I.C., Rixon, C.A.M. \& MacIsaac, H.J. (2006) Popularity and propagule pressure: determinants of introduction and establishment of aquarium fish. Biological Invasions, 8, 377-382.

Duncan, R.P. \& Williams, P.A. (2002) Darwin's naturalization hypothesis challenged. Nature, 417, 608-609.

Elton, C.S. (1958) The ecology of invasions by animals and plants. Methuen, London, UK.

Faith, D.P. (1992) Conservation evaluation and phylogenetic diversity. Biological Conservation, 61, 1-10.

Felsenstein, J. (1985) Phylogenies and the comparative method. American Naturalist, 125, 1-15.

Florida Fish and Wildlife Conservation Commission (1999-2010) Welcome to nonnative species information. Available at: http://www.myfwc.com/WILDLIFEHABITATS/ Nonnative_index.htm
Fritts, T.H. \& Rodda, G.H. (1998) The role of introduced species in the degradation of island ecosystems: a case history of Guam. Annual Review of Ecology and Systematics, 29, 113140.

Hall, T.A. (1999) BioEdit: a user-friendly biological sequence alignment editor and analysis program for Windows 95/98/ NT. Nucleic Acids Symposium Series, 41, 95-98.

Harmon, L.J., Harmon, L.L. \& Jones, C.G. (2007) Competition and community structure in diurnal arboreal geckos (genus Phelsuma) in the Indian Ocean. Oikos, 116, 1863-1878.

Huelsenbeck, J.P. \& Ronquist, F. (2001) MRBAYES: Bayesian inference of phylogenetic trees. Bioinformatics, 17, 754755.

Irschick, D.J., Gentry, G., Herrel, A. \& Vanhooydonck, B. (2006) Effects of sarcophagid fly infestations on Green Anole Lizards (Anolis carolinensis): an analysis across seasons and age/sex classes. Journal of Herpetology, 40, 107-112.

King, F.W., Nickerson, M.A. \& Krysko, K.L. (1996-2010) Florida Museum of Natural History's checklist of Florida amphibians and reptiles. Available at: http://www.flmnh. ufl.edu/herpetology/checklist/Flaherps.htm

Kraus, F. (2009) Alien reptiles and amphibians. A scientific compendium and analysis. Springer, Dordrecht, The Netherlands.

Lockwood, J.L., Cassey, P. \& Blackburn, T. (2005) The role of propagule pressure in explaining species invasions. Trends in Ecology and Evolution, 20, 223-228.

Luiselli, L. (2006) Food niche overlap between sympatric potential competitors increases with habitat alteration at different trophic levels in rain-forest reptiles (omnivorous tortoises and carnivorous vipers). Journal of Tropical Ecology, 22, 695-704.

Mack, R.N. (1996) Biotic barriers to plant naturalization. Proceedings of the IX International Symposium on biological control of weeds (ed. by V.C. Moran and J.H. Hoffmann), pp. 39-46, University of Cape Town, Cape Town.

Mack, R.N., Simberloff, D., Lonsdale, W.M., Evans, H., Clout, M. \& Bazzaz, F.A. (2000) Biotic invasions: causes, epidemiology, global consequences, and control. Ecological Applications, 10, 689-710.

Maddison, W.P. \& Maddison, D.R. (2009) Mesquite: a modular system for evolutionary analysis. Version 2.71. Available at: http://mesquiteproject.org.

Meshaka, W.E.J., Butterfield, B.P. \& Hauge, J.B. (2004) The exotic amphibians and reptiles of Florida. Krieger Publishing Company, Malabar, Florida.

Meshaka, W.E., Smith, H.T., Severson, R. \& Severson, M.A. (2005) Spatial picture of a gecko assemblage in flux. Biological Sciences, 68, 53-55.

Meshaka, W.E., Cress, H.L., Kingsland, K.L., Smith, H.T., Fitchett, S.A., Moore, J.A. \& Cowan, E.M. (2006) Hemidactylus (House Gecko) assemblage dynamics on south Florida buildings. Journal of Kansas Herpetology, 17, 7-8.

Nafis, G. (2000-2010) A guide to the reptiles and amphibians of California. Available at: http://www.californiaherps.com/ (accessed 28 September 2010). 
Nylander, J.A.A. (2004) MrModeltest v2. Program distributed by the author. Evolutionary Biology Centre, Uppsala University, Uppsala.

Oksanen, J., Blanchet, F.G., Kindt, R., Legendre, P., O'Hara, R.B., Simpson, G.L., Solymos, P., Stevens, M.H.H. \& Wagner, H. (2010) Vegan: community ecology package. Available at: http://cran.r-project.org/web/packages/vegan/ index.html.

Oliver, J.H., Hayes, M.P., Keirans, J.E. \& Lavender, D.R. (1993) Establishment of the foreign parthenogenetic tick Amblyomma rotundatum (Acari, Ixodidae) in Florida. Journal of Parasitology, 79, 786-790.

Procheş, Ş., Wilson, J.R.U., Richardson, D.M. \& Rejmánek, M. (2008) Searching for phylogenetic pattern in biological invasions. Global Ecology \& Biogeography, 17, 5-10.

Pyšek, P. (1998) Is there a taxonomic pattern to plant invasions? Oikos, 82, 282-294.

Pyšek, P., Richardson, D.M., Pergl, J., Jarošík, V., Sixtová, Z. \& Weber, E. (2008) Geographical and taxonomic biases in invasion ecology. Trends in Ecology and Evolution, 23, 237244.

R Development Core Team (2010) R: a language and environment for statistical computing. R Foundation for Statistical Computing. Vienna, Austria. ISBN 3-900051-07-0. Available at: http://www.R-project.org.

Rambaut, A. (1996) Se-Al: sequence alignment editor. http:// tree.bio.ed.ac.uk/software/seal/

Reaser, J.K., Meyerson, L.A. \& Von Holle, B. (2008) Saving camels from straws: how propagule pressure-based prevention policies can reduce the risk of biological invasion. Biological Invasions, 10, 1085-1098.

Reed, R.N. \& Rodda, G.H. (2009) Giant constrictors: biological and management profiles and an establishment risk assessment for nine large species of pythons, anacondas, and the boa constrictor. U.S. Geological Survey Open-File Report. 302 p. (URL: http://www.fort.usgs.gov/products/publications/pub_ abstract.asp?PubID=22691; last accessed 28 September 2010).

Rejmánek, M. (1996) A theory of seed plant invasiveness: the first sketch. Biological Conservation, 78, 171-181.

Ricciardi, A. \& Mottiar, M. (2006) Does Darwin's naturalization hypothesis explain fish invasions? Biological Invasions, 8, 1403-1407.

Richardson, D.M. \& Rejmánek, M. (2004) Invasive conifers: a global survey and predictive framework. Diversity and Distributions, 10, 321-331.

Richardson, D.M., Allsopp, N., D’Antonio, C.M., Milton, S.J. \& Rejmánek, M. (2000) Plant invasions: the role of mutualisms. Biological reviews of the Cambridge Philosophical Society, 75, 65-93.

Schulte, J.A.I., Valladares, J.P. \& Larson, A. (2003) Phylogenetic relationships within Iguanidae inferred using molecular and morphological data and a phylogenetic taxonomy of Iguanian lizards. Herpetologica, 59, 399-419.

Shirley, S.M. \& Kark, S. (2009) The role of species traits and taxonomic patterns in alien bird impacts. Global Ecology \& Biogeography, 18, 450-459.
Simberloff, D. (2009) The role of propagule pressure in biological invasions. Annual Review of Ecology, Evolution \& Systematics, 40, 81-102.

Strauss, S.Y., Webb, C.O. \& Salamin, N. (2006) Exotic taxa less related to native species are more invasive. Proceedings of the National Academy of Sciences USA, 103, 58415845.

Strong, D.R.J., Lawton, J.H. \& Southwood, T.R.E. (1984) Insects on plants: community patterns and mechanisms. Blackwell Scientific, Oxford.

Thuiller, W., Gallien, L., Boulangeat, I., de Bello, F., Münkemüller, T., Roquet, C. \& Lavergne, S. (2010) Resolving Darwin's naturalization conundrum: a quest for evidence. Diversity and Distributions, 16, 461-475.

Townsend, T.M., Larson, A., Louis, E. \& Macey, J.R. (2004) Molecular phylogenetics of Squamata: the position of snakes, Amphisbaenians, and Dibamids, and the root of the Squamate tree. Systematic Biology, 53, 735-757.

Vellend, M. (2010) Conceptual synthesis in community ecology. Quarterly Review of Biology, 85, 183-206.

Vidal, N. \& Hedges, S.B. (2005) The phylogeny of squamate reptiles (lizards, snakes, and amphisbaenians) inferred from nine nuclear protein-coding genes. Comptes Rendus Biologies, 328, 1000-1008.

Webb, C.O. (2000) Exploring the phylogenetic structure of ecological communities: an example from rain forests. American Naturalist, 156, 145-155.

Webb, C.O., Ackerly, D.D. \& Kembel, S.W. (2008) Phylocom: software for the analysis of phylogenetic community structure and trait evolution. Bioinformatics, 24, 20982100.

van Wilgen, N.J., Roura-Pascual, N. \& Richardson, D.M. (2009) A quantitative climate-match score for risk-assessment screening of reptile \& amphibian introductions. Environmental Management, 44, 590-607.

van Wilgen, N.J., Elith, J., Wilson, J.R.U., Wintle, B.A. \& Richardson, D.M. (2010) Alien invaders and reptile traders: what drives the live animal trade in South Africa? Animal Conservation, 13 (Suppl. 1), 24-32.

\section{SUPPORTING INFORMATION}

Additional Supporting Information may be found in the online version of this article:

Figure S1 Phylogenetic relationships of reptiles native and introduced to California inferred from two nuclear (c-mos and RAG 1) and three mitochondrial genes (cytb, ND2 and ND4).

Figure S2 Phylogenetic relationships of reptiles native and introduced to Florida inferred from two nuclear (c-mos and RAG 1) and three mitochondrial genes (cytb, ND2 and ND4).

Figure S3 A dendrogram representing the ecological distance between species native to and introduced to California.

Figure S4 A dendrogram representing the ecological distance between species native to and introduced to Florida. 
Appendix S1 More detail pertaining to methods, results and discussion of additional analyses performed including (S1.1) ordination analysis of 37 ecological traits to determine whether species with similar ecologies are close phylogenetic relatives and (S1.2) analysis using successfully established species in the same category as natives relative to species introduced subsequently.

Appendix S2 GENBANK accession numbers for sequences used in the construction of molecular phylogenies for introduced and native species in California and Florida.

As a service to our authors and readers, this journal provides supporting information supplied by the authors. Such materials are peer-reviewed and may be re-organized for online delivery, but are not copy-edited or typeset. Technical support issues arising from supporting information (other than missing files) should be addressed to the authors.

\section{BIOSKETCHES}

Nicola J. van Wilgen's $\mathrm{PhD}$ thesis through the Centre for Invasion Biology $(\mathrm{C} \bullet \mathrm{I} \bullet \mathrm{B}$; http://academic.sun.ac.za/cib/) at Stellenbosch University, South Africa, explored various aspects related to risk assessment for introduced reptiles and amphibians. She is interested in the use of scientific knowledge in integrated strategies for dealing with biological invasions and other environmental problems.

Dave Richardson is the Deputy Director: Science Strategy at the $\mathrm{C} \bullet \mathrm{I} \bullet \mathrm{B}$. His main research interest is the ecology of biological invasions, especially trees.

Editor: Ralph Mac Nally 